\title{
ALTERAÇÕES QUÍMICAS NO SOLO APÓS FERTIRRIGAÇÃO DO CAPIM MOMBAÇA COM ÁGUA RESIDUÁRIA DE CURTUME
}

\author{
Antonio Teixeira de Matos $^{1}$, Pedro de Oliveira Martins ${ }^{2}$, Paola Alfonsa Vieira Lo Monaco 3
}

\section{RESUMO}

Objetivou-se, com a realização deste trabalho, avaliar as alterações químicas no solo, proporcionadas pela aplicação de diferentes doses de água residuária de curtume (ARC) no capim Mombaça (Panicum maximum cv. Mombaça). Com base na composição química da água residuária, foram estabelecidas as doses de aplicação da $\mathrm{ARC}: \mathrm{T}_{1}=0,0 ; \mathrm{T}_{2}=1,5$; $\mathrm{T}_{3}=3,0 ; \mathrm{T}_{4}=5,0 ; \mathrm{T}_{5}=10,0$ e $\mathrm{T}_{6}=15,0 \mathrm{~kg} \cdot \mathrm{ha}^{-1}$ de crômio. De acordo com os resultados obtidos, pôde-se concluir que a água residuária de curtume proporcionou diminuição nas concentrações de $\mathrm{P}$ e $\mathrm{K}$ disponíveis no solo, o que esteve associado, provavelmente, à maior absorção desses elementos químicos pelas plantas, em decorrência das melhorias na fertilidade do solo. As concentrações de nitrogênio total se mantiveram praticamente inalteradas, enquanto as de sódio aumentaram com o aumento da dose de ARC. O crômio, na sua forma disponível, não foi detectado no solo, nem nas maiores doses de ARC aplicadas.

Palavras-chave: disposição de águas residuárias, crômio, forrageiras.

\section{ABSTRACT \\ CHEMICAL ALTERATIONS IN SOIL AFTER FERTIGATON OF MOMBASA GRASS WITH TANNERY WASTEWATER}

The objective of this study was to evaluate the chemical alterations in soil resultant from the application of different doses of tannery wastewater (ARC) on Mombasa grass (Panicum maximum cv. Mombasa). Based on the chemical composition of the wastewater the following application doses of ARC were established: $\mathrm{T}_{1}=0.0 ; \mathrm{T}_{2}=1.5 ; \mathrm{T}_{3}=3.0$; $\mathrm{T}_{4}=5.0 ; \mathrm{T}_{5}=10.0 \mathrm{e} \mathrm{T}_{6}=15.0 \mathrm{~kg} \cdot \mathrm{ha}^{-1}$ of chromium. According to the results obtained it was concluded that the tannery wastewater provided a reduction in the concentrations of available $\mathrm{P}$ and $\mathrm{K}$ in the soil, which was probably a result of increased absorption of these elements by plants. The total nitrogen concentrations remained virtually unchanged, while sodium increased with elevated ARC doses. Chromium, in its available form, was not detected in soil even in the larger doses applied.

Keywords: wastewater disposal, chromium, forage.

\section{Recebido para publicação em 17/06/2013. Aprovado em 20/08/2013.}

1 - Engenheiro Agrícola, D.S. em Solos e Nutrição de Plantas e Professor Associado do Departamento de Engenharia Agrícola da Universidade Federal de Viçosa (DEA/UFV). E-mail: atmatos@ufv.br.

2 - Engenheiro Ambiental, M.S. em Engenharia Agrícola e Professor do Centro Universitário Luterano de Palmas (CEULP/ ULBRA). E-mail: pedrooliveira96@yahoo.com.br.

3 - Engenheira Agrícola, D.S. em Engenharia Agrícola e Professora do Instituto Federal de Educação, Ciência e Tecnologia do Espírito Santo - campus Centro Serrano. E-mail: paolalomonaco2004@yahoo.com.br.

\section{REVENG} $128-137 \mathrm{p}$.

ENGENHARIA NA AGRICULTURA, VIÇOSA - MG, V.22 N.2, MARÇO / ABRIL 2014 


\section{INTRODUÇÃO}

Em estados em que a atividade econômica está baseada na agropecuária, como é o caso do Tocantins, a agroindústria de processamento de peles é uma das mais importantes, aumentando o valor agregado ao couro, sendo um setor econômico responsável pela geração de grande quantidade de empregos e receita para o Estado.

Alguns curtumes processam o couro somente até a fase de curtimento (adição de substâncias químicas para torná-lo mais durável e melhorar suas características físicas), quando é produzido o denominado "wet blue", forma primária de seu tratamento e que, como tal, já possibilita sua comercialização. O couro wet blue não apresenta especificações definidas de espessura, cor, maciez e conteúdo de água, sendo por isso considerado um produto primário dos curtumes (MATOS, 2010).

Um dos grandes problemas ambientais associados aos curtumes é a poluição causada pelos seus resíduos, os quais possuem elevadas cargas orgânicas e inorgânicas. Dentre os poluentes inorgânicos, o crômio trivalente, utilizado no processo de curtimento do couro (CASTILHOS et al., 2002; CAVALLET et al., 2007; FREITAS; MELNIKOV, 2006) é o que maior preocupação desperta.

Uma medida de controle ambiental que vem sendo praticada atualmente, em grande escala, para tratamento de efluentes de empreendimentos agroindustriais é a disposição no solo por intermédio da fertirrigação. Essa prática tem sido cada vez mais frequente em diversos países e também no Brasil, trazendo como benefício o aproveitamento, por parte da cultura, dos nutrientes presentes no efluente, possibilitando a preservação dos cursos d'água, já que deixarão de receber essas cargas poluentes. De acordo com Lo Monaco et al. (2009), se realizada de forma adequada, a fertirrigação pode possibilitar aumento na produtividade, reduzir a poluição ambiental, além de promover melhoria nas características químicas, físicas e biológicas do solo.

Vários trabalhos comprovam a eficiência de resíduos de curtume como bons fertilizantes e corretivos de acidez dos solos (KONRAD; CASTILHOS, 2002; FERREIRA et al., 2003; ARAÚJO et al., 2005; ARAÚJO et al., 2008). No entanto, em razão da elevada concentração de crômio em águas residuárias de curtume, principalmente naquelas em que há recirculação do efluente no processo, cuidado especial deve ser dado à disposição final desses resíduos, já que, de acordo com Conceição et al. (2007), esse metal, na forma hexavalente $\left(\mathrm{Cr}^{6+}\right)$, é tóxico, sendo considerado mutagênico e carcinogênico. Essa forma iônica é também muito solúvel e, por esta razão, se movimenta em velocidades próximas à da água em percolação, podendo vir a contaminar águas subterrâneas. O crômio trivalente $\left(\mathrm{Cr}^{3+}\right)$, ao contrário, apresenta toxicidade relativamente baixa, permanecendo imóvel em ambientes moderadamente alcalinos e levemente ácidos (FACHIN et al., 2006).

$\mathrm{O}$ crômio trivalente é fortemente adsorvido nas caulinitas e montmorilonitas em solos muito ácidos ( $\mathrm{pH}$ menor do que 3,6); em $\mathrm{pH}$ maior que 5,5, forma óxidos e hidróxidos estáveis e de baixíssima solubilidade (RAY et al., 1989; RUTLAND, 1991). Em $\mathrm{pH}$ acima de 5,5, compostos orgânicos podem complexar o $\mathrm{Cr}$ (III), mantendo-o solúvel até que encontre condições de precipitação. No caso de pH entre 5,5 e 12,0, as formas não complexadas precipitam, quase que completamente, como $\mathrm{Cr}(\mathrm{OH})_{3}$, em razão de sua baixa solubilidade (Kps de 2,9 x 10-29) (RAY et al., 1989).

A oxidação do $\mathrm{Cr}^{3+}$ a $\mathrm{Cr}^{6+}$ não é uma reação comum no solo, ocorrendo, entretanto, em condições de adequado conteúdo de água e na presença de altas concentrações de manganês facilmente redutível (TREBIEN, 1994; AQUINO NETO; CAMARGO, 2000). Trebien (1994) constatou, também, que a oxidação do crômio trivalente será menor se ele formar complexos orgânicos, tendo atribuído a não oxidação do $\mathrm{Cr}^{3+}$ 
em lodo da indústria de curtume a este fato.

Em razão do pouco conhecimento que se tem dos impactos proporcionados e os riscos ambientais decorrentes da aplicação da água residuária de curtume (ARC) no solo, objetivouse, com a realização desse trabalho, avaliar as alterações químicas no solo proporcionadas pela aplicação de diferentes doses de ARC em capim Mombaça (Panicum maximum cv. Mombaça), cultivado em um Latossolo Vermelho distrófico típico do cerrado do Estado de Tocantins.

\section{MATERIAL E MÉTODOS}

O experimento foi implantado e conduzido na área experimental do Departamento de Recursos Hídricos/Engenharia Agrícola do CEULPULBRA, em Palmas-TO, em casa de vegetação telada, não climatizada.

O solo utilizado no experimento foi coletado na camada arável (0-20 cm), numa área de cerrado virgem, portando sem registro de utilização agrícola anterior. O solo da área foi classificado como Latossolo Vermelho distrófico, segundo o sistema de classificação de solos da Empresa Brasileira de Pesquisa Agropecuária - EMBRAPA (1997). O material de solo foi coletado, de forma aleatória, em área de 0,50 ha, sendo as amostras simples posteriormente misturadas, formando uma amostra composta.

Após a coleta, as amostras foram encaminhadas ao Laboratório de Fertilidade do Solo e Física do Solo do DPS/UFV, para análises químicas e físicas, respectivamente, obedecendo-se metodologia proposta pela EMBRAPA (1997). No laboratório, foram determinadas as seguintes variáveis: $\mathrm{pH}$ em água, conteúdo de matéria orgânica, nitrogênio total, concentrações disponíveis de fósforo, crômio (todas formas químicas) e potássio e trocáveis de cálcio, magnésio e alumínio, além da acidez potencial (Quadro 1).

A água residuária utilizada para fertirrigação das plantas foi proveniente de um curtume no qual ocorre o processamento de peles em nível wet blue, localizado no município de Porto Nacional, TO, a qual foi armazenada em um reservatório de PVC, com capacidade de 0,35 $\mathrm{m}^{3}$, instalado próximo ao local do experimento e ao abrigo da luz.

O capim-mombaça (Panicum maximum cv. Mombaça) foi escolhido para ser cultivado em razão de exigir solo fértil, profundo, bem drenado, clima quente e precipitação anual superior a $1.000 \mathrm{~mm}$, tal como ocorre na região de Tocantins, podendo ser boa opção de cultivo em áreas onde será aplicada a água residuária de curtume (ARC).

Para caracterização da água residuária, as análises foram realizadas nos Laboratórios de Qualidade da Água e de Química dos Resíduos do Departamento de Engenharia Agrícola da Universidade de Viçosa-MG, em conformidade com a metodologia descrita no Standard Methods for the Examination of Water and Wastewater (APHA et al., 2005). No Quadro 2 estão apresentados os resultados das análises físicas, químicas e bioquímicas, bem como os respectivos métodos utilizados nas análises.

Quadro 1. Características químicas do solo utilizado no experimento

\begin{tabular}{|c|c|c|c|c|c|c|c|c|c|}
\hline \multirow{2}{*}{$\mathrm{pH}$} & $P_{\text {disp }}$ & $\mathrm{K}_{\text {disp }}$ & $\mathrm{Cr}_{\text {disp }}$ & N-total & M.O. & $\mathrm{Ca}^{+2}$ & $\mathrm{Mg}^{+2}$ & $\mathrm{Al}^{+3}$ & $\mathrm{H}+\mathrm{Al}$ \\
\hline & \multicolumn{5}{|c|}{-------- $\mathrm{mg} \mathrm{dm}^{-3}$-------- } & \multicolumn{4}{|c|}{----------- $\mathrm{cmol}_{\mathrm{c}} \mathrm{dm}^{-3}$----------- } \\
\hline 5,13 & 1,10 & 9,00 & N.D. & 0,13 & 4,13 & 0,15 & 0,03 & 0,19 & 9,20 \\
\hline
\end{tabular}

pH em água (1:2,5); $\mathrm{P}_{\text {disp }}, \mathrm{K}_{\text {disp }}$ e $\mathrm{Cr}_{\text {disp }}$ : extrator Mehlich 1 e quantificação por fotometria de chama e absorção atômica; $\mathrm{N}$ : quantificação utilizando-se o método semi-micro Kjeldahl; M.O.: C.O. x 1,724, sendo C.O. quantificado utilizandose o método Walkley-Black; $\mathrm{Ca}^{2+}, \mathrm{Mg}^{2+}, \mathrm{Al}^{3+}$ trocáveis: extrator: $\mathrm{KCl} 1 \mathrm{~mol} \mathrm{~L}{ }^{-1}$ e determinação por titulometria; e $(\mathrm{H}+\mathrm{Al})$ : extrator acetato de cálcio $0,5 \mathrm{~mol} \mathrm{~L}^{-1}, \mathrm{pH}$ 7,0 e quantificação por titulometria.

ND - não detectado. 
Quadro 2. Resultado das análises físicas, químicas e bioquímicas da água residuária de curtume

\begin{tabular}{lcc}
\hline Variáveis & Resultado & Método \\
\hline $\mathrm{pH}$ & 9,04 & Peagâmetro de bancada \\
\hline Cond. Elétrica & $21,89 \mathrm{dS} \mathrm{m}^{-1}$ & Condutivímetro de bancada \\
\hline $\mathrm{DQO}$ & $9.240 \mathrm{mg} \mathrm{L}^{-1}$ & Método de oxidação química em refluxo aberto \\
\hline $\mathrm{DBO}$ & $5.028 \mathrm{mg} \mathrm{L}^{-1}$ & $\begin{array}{c}\text { Quantificação do oxigênio dissolvido pelo método } \\
\text { iodométrico (Processo Winkler) }\end{array}$ \\
\hline $\mathrm{N}_{\text {Total }}$ & $1.367 \mathrm{mg} \mathrm{L}^{-1}$ & Processo Semimicro Kjeldahl \\
\hline $\mathrm{N}_{\text {Amon }}$ & $1.192 \mathrm{mg} \mathrm{L}^{-1}$ & Processo Semimicro Kjeldahl sem digestão \\
\hline $\mathrm{P}_{\text {Total }}$ & $2,00 \mathrm{mg} \mathrm{L}^{-1}$ & Fotometria de chama \\
\hline $\mathrm{Ca}_{\text {Total }}$ & $153 \mathrm{mg} \mathrm{L}^{-1}$ & \\
$\mathrm{Mg}_{\text {Total }}$ & $275 \mathrm{mg} \mathrm{L}^{-1}$ & \\
$\mathrm{~K}_{\text {Total }}$ & $52 \mathrm{mg} \mathrm{L}^{-1}$ & \\
$\mathrm{Na}_{\text {Total }}$ & $9.812 \mathrm{mg} \mathrm{L}^{-1}$ & \\
\hline $\mathrm{Cr}_{\text {Total }}$ & $3,40 \mathrm{mg} \mathrm{L}^{-1}$ & \\
$\mathrm{Al}_{\text {Total }}$ & $\mathrm{ND}$ & \\
$\mathrm{Fe}_{\text {Total }}$ & $\mathrm{ND}$ & \\
$\mathrm{Cu}_{\text {Total }}$ & $\mathrm{ND}$ & \\
$\mathrm{Mn}_{\text {Total }}$ & $\mathrm{ND}$ & \\
$\mathrm{Zn}_{\text {Total }}$ & \\
$\mathrm{Cd}_{\text {Total }}$ & $\mathrm{ND}$ & \\
$\mathrm{Pb}_{\text {Total }}$ & & \\
$\mathrm{Ni}_{\text {Total }}$ & \\
$\mathrm{ND}_{- \text {não detectado. }}$ & \\
\hline
\end{tabular}

$\mathrm{ND}$ - não detectado.

O solo foi acondicionado em vasos de $5 \mathrm{~L}$, tendo seu pH corrigido até 6,0 , com a adição de calcário dolomítico (PRNT 85\%), na proporção de 2,5 tha1. Na correção da fertilidade foi utilizado adubo mineral de formulação NPK 4-14-8, na proporção de $50 \mathrm{~kg} \cdot \mathrm{ha}^{-1}$, conforme orientações do órgão de extensão rural do Estado do Tocantins. O plantio do capim mombaça foi feito por semente, utilizandose um total, aproximado, de 30 sementes por vaso.

Decorrido um período de 18 dias após o plantio, efetuou-se um desbaste nos vasos, deixandose 12 plantas em cada um deles. Os vasos foram dispostos em fileiras distanciadas de 1 metro entre elas, sendo a distância entre vasos de $0,50 \mathrm{~m}$, a fim de se evitarem sombreamentos.

Com base na composição química da água residuária (Quadro 2), foram estabelecidas as taxas de aplicação da ARC: $\mathrm{T}_{1}=0 \mathrm{~kg} \cdot \mathrm{ha}^{-1}$ de crômio, $\mathrm{T}_{2}=$ $1,5 \mathrm{~kg} \cdot \mathrm{ha}^{-1}$ de crômio, $\mathrm{T}_{3}=3,0 \mathrm{~kg} \cdot \mathrm{ha}^{-1}$ de crômio, $\mathrm{T}_{4}$ $=5,0 \mathrm{~kg} \cdot \mathrm{ha}^{-1}$ de crômio, $\mathrm{T}_{5}=10,0 \mathrm{~kg} \cdot \mathrm{ha}^{-1}$ de crômio e $\mathrm{T}_{6}=15,0 \mathrm{~kg} \cdot \mathrm{ha}^{-1}$ de crômio.

Com base nessas doses, as lâminas de água residuária aplicadas foram 44, 103, 147, 294 e $441 \mathrm{~mm}$, respectivamente para os tratamentos $\mathrm{T}_{2}$, $\mathrm{T}_{3}, \mathrm{~T}_{4}, \mathrm{~T}_{5}$ e $\mathrm{T}_{6}$. No Quadro 3 estão apresentadas as cargas de elementos químicos aplicadas ao solo, 
Quadro 3. Referencial de exportação de nutrientes pela cultura de Panicum maximum e doses de elementos químicos aplicadas ao solo $\left(\mathrm{kg} \mathrm{ha}^{-1}\right)$, de acordo com as lâminas de água residuária de curtume nele dispostas

\begin{tabular}{|c|c|c|c|c|c|c|}
\hline \multirow[t]{2}{*}{ Nutrientes } & \multirow[t]{2}{*}{ Exportação de nutrientes $^{(1)}$} & \multicolumn{5}{|c|}{ Lâminas (mm) } \\
\hline & & 44 & 103 & 147 & 294 & 441 \\
\hline $\mathrm{K}_{\text {Total }}$ & 600 & 22,8 & 54,0 & 76,4 & 153,0 & 229,4 \\
\hline $\mathrm{N}_{\text {Total }}$ & 560 & 600,6 & $1.420,9$ & $2.009,1$ & $4.022,3$ & $6.031,4$ \\
\hline $\mathrm{P}_{\text {Total }}$ & 77 & 0,9 & 2,1 & 2,9 & 5,9 & 8,8 \\
\hline $\mathrm{Ca}_{\text {Total }}$ & 230 & 67,3 & 159,0 & 224,9 & 450,2 & 675,1 \\
\hline $\mathrm{Mg}_{\text {Total }}$ & 133 & 120,8 & 285,8 & 404,2 & 809,2 & $1.213,3$ \\
\hline $\mathrm{Cr}_{\text {Total }}$ & - & 1,5 & 3,5 & 5,0 & 10,0 & 15,0 \\
\hline $\mathrm{Na}_{\text {Total }}$ & - & $4.311,3$ & $10.198,5$ & $14.420,6$ & $28.871,1$ & $43.290,9$ \\
\hline
\end{tabular}

(1) valores obtidos considerando-se uma produtividade de $35 \mathrm{tha}^{-1}$ do capim guiné (SANCHEZ, 1975)

de acordo com as doses de ARC aplicadas, e a exportação de nutrientes por uma espécie do mesmo gênero do capim mombaça, para ser tomada como referencial, em termos de necessidades da cultura por nutrientes.

A aplicação da água residuária foi feita utilizando-se de um regador manual, de forma a se propiciar o contato da água residuária com as folhas do capim, simulando-se a aplicação por meio de sistemas de aspersão. A primeira dose de água residuária foi aplicada 20 dias após o plantio do capim e as aplicações subsequentes foram feitas uma vez por semana.

Para definir a quantidade de água a ser aplicada e garantir o conteúdo de água adequado para atingir a capacidade de campo, considerou-se um volume de $50 \%$ de poros no solo de cada vaso, correspondendo a capacidade de campo do solo $50 \%$ de ocupação desses poros com água. Assim, a determinação foi feita por meio da pesagem de todos os vasos, anotando-se a massa inicial de cada um. Em seguida, adicionou-se 1,25 L de água de rede de abastecimento (proveniente de um poço tubular profundo, o qual abastece todas as instalações do Centro Universitário Luterano de Palmas), objetivando-se o preenchimento de $50 \%$ do volume de poros do solo contido no vaso. Depois de efetuado esse procedimento, pesaram-se, novamente, os vasos, determinando-se a massa final de cada vaso. Dessa forma, por meio de pesagem, passou-se a controlar e a efetuar a reposição de água da rede de abastecimento nos vasos, sempre com o intuito de manter o solo com conteúdo de água próximo ao da capacidade de campo. A reposição de água nos vasos foi feita duas vezes ao dia, pela manhã e à tarde, porém nos meses de agosto e setembro, devido à baixa umidade relativa do ar, período em que a quantidade evapotranspirada foi muito grande, tornou-se necessária a reposição de água, também, ao meio dia.

Nos vasos submetidos aos tratamentos $\mathrm{T}_{2}, \mathrm{~T}_{3}$, $\mathrm{T}_{4}, \mathrm{~T}_{5}$ e $\mathrm{T}_{6}$ foram aplicados, respectivamente, os seguintes volumes totais de água residuária: 1,45 L; 3,43 L; 4,85 L; 9,71 L e 14,56 L. Esses volumes foram divididos em 10 aplicações semanais, durante o período de 24 de junho a 07 de setembro de 2009. As menores lâminas de $\operatorname{ARC}(44,103$ e $147 \mathrm{~mm}$ ), foram aplicadas de uma só vez, enquanto as maiores lâminas (294 e $441 \mathrm{~mm}$ ) foram aplicadas em duas e três vezes, respectivamente, ao longo do mesmo dia.

Ao final do experimento, procedeu-se outra coleta de amostras compostas de solo, depois que o material de todo o vaso foi homogeneizado. As análises efetuadas foram as mesmas efetuadas no solo antes da aplicação da ARC e fertirrigação, excetuando-se $\mathrm{Ca}^{+2}, \mathrm{Mg}^{+2}, \mathrm{Al}^{+3}$ e $\mathrm{H}+\mathrm{Al}$, seguindose idênticos métodos de análise. Foi realizada

\section{REVENG}


também a análise da condutividade (CE), a qual foi medida no extrato da pasta de saturação, obtida na proporção de 1:5, conforme metodologia descrita em Matos (2008).

$\mathrm{O}$ delineamento experimental usado foi o inteiramente casualizado (DIC), com quatro repetições e cinco doses de crômio. $\mathrm{Na}$ análise estatística, os dados foram analisados utilizando-se o programa de estatística SAEG 9.1 (EUCLYDES, 1983) para realização da análise de variância (Anova) e, posteriormente, as médias foram comparadas utilizando-se o teste de Dunnett, com $5 \%$ de significância.

\section{RESULTADOS E DISCUSSÃO}

No Quadro 4 estão apresentados os resultados de análise química do solo coletado em cada parcela experimental, após a aplicação dos tratamentos.

Com base nos resultados obtidos (Quadro 4), observa-se que algumas variáveis diferiram significativamente $(\mathrm{P}<0,05)$ das obtidas no tratamento controle em que não foi aplicada a $\mathrm{ARC}$, mas apenas água da rede de abastecimento.

Em relação ao teor de matéria orgânica no solo, não foi observada diferença significativa entre os tratamentos de aplicação da ARC, o que comprova que a quantidade de ARC aplicada não foi suficiente para adicionar quantidades apreciáveis de matéria orgânica ao solo.

Em relação ao pH, não foi observada alteração proporcionada pela aplicação de doses crescentes da ARC no solo (Quadro 4). Araújo et al. (2008) observaram aumento no $\mathrm{pH}$ do solo com a aplicação de doses de 2,5 e $5 \mathrm{t} \mathrm{ha}^{-1}$ de lodo "in natura" e "compostado", gerado no tratamento de água residuária de curtume e Ferreira et al. (2003) que, aplicando o mesmo resíduo, constataram redução na acidez e aumento no teor de cálcio trocável no solo. Há de se ressaltar que, nas pesquisas citadas, os autores utilizaram lodo e não água residuária, material sabidamente possuidor de maior concentração de sólidos, cuja carga aplicada proporciona maior influência no $\mathrm{pH}$ do solo.

No que se refere à condutividade elétrica, verificou-se que a adição de sais presentes na ARC proporcionou aumento nessa variável, quando comparado aos valores medidos em amostras de solo coletadas no tratamento testemunha. A elevação da condutividade elétrica no solo pode ser atribuída à elevada concentração de sais, especialmente de sódio, na ARC (Quadro 2) aplicada ao solo. Lo Monaco et al. (2009), de forma semelhante, também constataram que a aplicação de água residuária do processamento dos frutos do cafeeiro provocou aumento na concentração de potássio trocável, o que proporcionou aumento na CE no solo cultivado com cafeeiro. De acordo com os autores, o sódio, tal como potássio, por ser um elemento químico que não está associado à matéria orgânica, permanece em solução e contribui, de forma acentuada, para a CE da solução.

A concentração de nitrogênio não aumentou no

Quadro 4. Caracterização química do solo coletado após o período de aplicação da água residuária da indústria do curtume em diferentes doses

\begin{tabular}{|c|c|c|c|c|c|c|c|}
\hline \multirow{2}{*}{$\begin{array}{c}\text { Tratamentos } \\
\left(\mathrm{kg} \mathrm{ha}^{-1} \mathrm{de} \mathrm{Cr}_{\text {Total }}\right)\end{array}$} & \multirow{2}{*}{$\mathrm{pH}$} & $\mathrm{CE}$ & $\mathrm{N}$ & $\mathrm{P}_{\text {disp }}$ & $\mathrm{K}_{\text {disp }}$ & $\mathrm{Cr}_{\text {disp }}$ & MO \\
\hline & & $\mathrm{dS} \mathrm{m}^{-1}$ & dag $\mathrm{kg}^{-1}$ & \multicolumn{4}{|c|}{--------- $\mathrm{mg} \mathrm{dm}{ }^{-3}$} \\
\hline 0 & 6,76 & 0,085 & 0,10 & 6,1 & 106 & ND & 4,61 \\
\hline 1,5 & 6,59 & $0,126^{*}$ & 0,09 & $3,5^{*}$ & $45^{*}$ & ND & 4,48 \\
\hline 3,0 & 6,76 & $0,135^{*}$ & 0,10 & $2,3^{*}$ & $41^{*}$ & ND & 4,09 \\
\hline 5,0 & 6,56 & $0,152 *$ & 0,10 & $2,3^{*}$ & $39 *$ & ND & 4,09 \\
\hline 10,0 & 6,38 & $0,234^{*}$ & 0,11 & $2,1^{*}$ & $42 *$ & ND & 4,35 \\
\hline 15,0 & 6,46 & $0,236^{*}$ & 0,11 & $3,1 *$ & $38^{*}$ & ND & 4,48 \\
\hline
\end{tabular}

Em cada variável, médias que diferiram do tratamento controle pelo teste de Dunnett a 5\% de probabilidade. 
solo, ainda que grandes e crescentes quantidades tenham sido aplicadas via ARC. Isso pode ser decorrente da absorção pelas plantas, perdas e baixa precisão das análises.

No caso do fósforo e do potássio disponíveis, observou-se influência negativa, ou seja, decréscimo na concentração no solo, após a aplicação da ARC. No que se refere ao fósforo, isso ocorreu, possivelmente, em decorrência da intensiva absorção pelas plantas proporcionada com a aplicação da ARC, uma vez que, conforme pode ser verificado na Quadro 3, as quantidades de macronutrientes aplicadas via ARC foram suficientes para estimular o crescimento das plantas. Embora sejam reportados, na literatura, efeitos benéficos à microbiota (KONRAD; CASTILHOS, 2001) e, com isso, maior disponibilização de fósforo no solo receptor de lodo de tratamento de ARC (RICHARDSON, 2001), aparentemente isso foi fator de menor intensidade que a adsorção na matriz do solo. Solos oxídicos típicos do cerrado, tal como o Latossolo Vermelho (LVd), apresentam elevado teor de argila, com predomínio de óxidos de ferro e de alumínio, minerais que adsorvem fortemente o fósforo, diminuindo sua disponibilidade no meio (NOVAIS et al., 2007 e PARFIT et al., 1975). Isso explicaria não ter sido verificado aumento na disponibilidade desse nutriente, mesmo tendo sido aplicadas doses crescentes da ARC.

No caso do potássio, a não verificação de aumento na sua concentração disponível no solo foi decorrente das doses relativamente baixas que foram aportadas ao solo em relação às necessidades da cultura (Quadro 3). Com isso, acredita-se que o potássio adicionado e parte do já disponível no solo tenham sido absorvidos pelas plantas.

As análises do solo realizadas no presente trabalho indicaram ausência de crômio na forma disponível no solo, antes da implantação do experimento (Quadro 1) e também após a conclusão do mesmo (Quadro 4), indicando que, mesmo nas maiores doses, a capacidade adsortiva de maior energia do solo não foi ultrapassada.

Os metais podem ser retidos de diferentes formas no solo, onde podem ser adsorvidos nos sítios de carga negativa, por forças eletrostáticas, ou em sítios de adsorção específica, na adsorção associada a ligações covalentes, que é uma forma de adsorção de alta energia. Além disso, os metais podem ser complexados por compostos orgânicos, adsorvidos ou oclusos em carbonatos ou óxidos de Fe, Al e Mn (MATOS et al., 1996). A não detecção de crômio disponível na análise final do solo indica que este elemento químico deve ficar fortemente adsorvido no solo, não sendo removível por extratores ácidos fracos, tal como o Mehlich 1. No entanto, torna-se importante frisar que a não detecção do metal não é indicativo que o $\mathrm{Cr}$ não esteja presente no solo, mas apenas de que não esteja disponível para plantas ou para ser lixiviado para águas subterrâneas.

As plantas apresentaram tendência de decréscimo de produtividade de matéria seca com a aplicação de doses superiores à faixa de 2.734 a $3.375 \mathrm{~m}^{3} \mathrm{ha}^{-1}$, ou seja, 9,02 a 12,46 $\mathrm{kg} \mathrm{ha}^{-1} \mathrm{de} \mathrm{Cr}$, dependendo da idade de corte efetuado nas plantas. Também houve tendência de decréscimo na produtividade de matéria seca e de proteína bruta nas plantas, com a idade do corte e esteve associado a problemas de desbalanço químico no solo e/ou problemas osmóticos no meio (OLIVEIRA et al., 2013).

Para avaliar o comportamento do solo e da planta frente à presença do metal crômio, Ferreira et al. (2003) realizaram estudos objetivando avaliar o efeito da adição de resíduos de curtume e rejeito carbonífero sobre características químicas do solo e sobre as plantas cultivadas em um Argissolo Vermelho distrófico, tendo concluído que os teores de $\mathrm{Cr}, \mathrm{Ni}, \mathrm{Cd}$ e Zn, determinados na parte aérea dos grãos e no solo, não foram influenciados pela adição dos resíduos, quando comparados os resultados com os obtidos no tratamento testemunha.

Araújo et al. (2008), ao avaliarem as alterações químicas no solo e o crescimento de plantas de milho em Argissolo Vermelho Amarelo, constataram que a quantidade máxima de lodo de curtume aplicada, $5 \mathrm{t} \mathrm{ha}^{-1}$, equivalente a $9 \mathrm{~kg} \mathrm{ha}^{-1} \mathrm{de}$ crômio aplicado, proporcionou ganhos em termos de desenvolvimento de plantas de milho. O acúmulo de crômio no solo também foi muito baixo, ou seja, abaixo de $1 \mathrm{mg} \mathrm{kg}^{-1} \mathrm{em}$ amostras analisadas de todos os tratamentos, valor este muito inferior ao valor de intervenção $\left(300 \mathrm{mg} \mathrm{kg}^{-1}\right)$ indicado na legislação ambiental estadual (CETESB, 2001) e federal (CONAMA, 2006). Os autores afirmaram que a disposição do resíduo, utilizando-se lodo com 
baixo teor de crômio e nas quantidades avaliadas (2,5 e $\left.5 \mathrm{t} \mathrm{ha}^{-1}\right)$, possibilita ganhos agrícolas com reduzidos impactos ambientais.

No planejamento da execução deste trabalho, o crômio foi considerado o elemento químico merecedor de maior preocupação e, por esta razão tomado como referência para definição das doses aplicadas de ARC. No entanto, com a condução do experimento, constatou-se que o sódio $(\mathrm{Na})$ deveria ter sido tomado como o elemento químico referência para definição das doses a serem aplicadas, tendo em vista a sua elevada disponibilidade na água residuária, pelo menos no caso deste trabalho. A explicação para a alta concentração de sódio na ARC é a forma de tratamento para conservação das peles. Quando as peles do curtume precisam ser estocadas ou transportadas, devem ser conservadas para evitar a proliferação de micro-organismos.

Como no Estado do Tocantins a produção de pele é muito dispersa, estando geralmente longe dos curtumes, o produtor tem que aguardar por semanas para que o material seja recolhido e conduzido para processamento. Nesse caso, para se evitar a proliferação de micro-organismos e, consequentemente, proporcionar maior conservação das peles, tem sido comum a realização da sua "cura", efetuada por meio da aplicação de grande quantidade de $\mathrm{NaCl}$ sobre elas. Assim, por ocasião do processamento, as peles terão que ser lavadas e, com isso, o efluente do processo tornase muito rico em $\mathrm{Na}$. Embora não tenha sido feita análise de Na no solo, a expectativa é a de que os teores tenham ficado muito altos, considerando-se as grandes quantidades de $\mathrm{Na}$ aplicadas via ARC.

Ao serem mantidas as doses aplicadas de ARC, de forma contínua, numa mesma área, é de se esperar que ou o solo passe a apresentar condição salina, caso a precipitação na região seja baixa ou a drenagem seja deficiente, ou, em caso contrário, as águas subterrâneas serão contaminadas. Ambas as condições devem ser consideradas inadequadas, caso se queira praticar agricultura sustentável. Dessa forma, efluentes de curtume cujas agroindústrias conservem as peles em salmouras, podem ser aproveitados na fertirrigação de culturas agrícolas, desde que o sódio seja tomado como elemento químico referência para definição das doses a serem aplicadas no solo.

\section{CONCLUSÃO}

De acordo com os resultados obtidos, pôde-se concluir que:

- A água residuária de curtume proporcionou diminuição nas concentrações de fósforo e potássio disponíveis no solo;

- As concentrações de nitrogênio total se mantiveram praticamente inalteradas;

- Não houve acúmulo de crômio, na forma disponível, no solo, mesmo tendo sido aplicadas doses de até $15 \mathrm{~kg} \mathrm{ha}^{-1}$, via água residuária do curtume;

\section{REFERÊNCIAS BIBLIOGRÁFICAS}

APHA - American Public Health Association; AWWA - American Water Works Association; WEF - Water Environment Federation. Standard methods for the examination of water and wastewater. 21.ed. Washington: APHA/AWWA/ WEF, 2005. 1268p.

ARAUJO, F.F.; TIRITAN, C.S.; CRESTE, J.E. Desenvolvimento da cultura do milho em solo tratado com lodo de curtume In: Congresso Brasileiro de Ciência do Solo, 30, 2005, Recife. Anais... Recife: UFRPE, 2005. CD Rom .

ARAÚJO, F.F.; TIRITAN, C.S.; PEREIRA, M.H.; CAETANO JÚNIOR, O. Desenvolvimento do milho e fertilidade do solo após aplicação de lodo de curtume e fosforita. Revista Brasileira de Engenharia Agrícola e Ambiental, Campina Grande, PB, v.5, p.507-511, 2008.

AQUINO NETO, V.; CAMARGO, A. Crescimento e acúmulo de crômio em alface cultivada em dois Latossolos tratados com $\mathrm{CrCl} 3$ e resíduo de curtume. Revista Brasileira de Ciência do Solo, Viçosa, v.24, p.225-235, 2000.

CAVALLET, L.E.; SELBACH, P.A.; GIANELLO, C. Concentração de crômio no sistema solo-plantapercolado em função da aplicação de resíduos de curtume em um argissolo de Estância Velha (RS). Revista Scientia Agraria, Curitiba, v.8, n.1, p.8793, 2007. 
CASTILHOS, D.D.; TEDESCO, M.J.; VIDOR, C. Rendimento de culturas e alterações químicas do solo tratado com resíduos de curtume e crômio hexavalente. Revista Brasileira de Ciência do Solo, Viçosa, v.26, p.1083-1092, 2002.

COMPANHIA DE TECNOLOGIA EM SANEAMENTO AMBIENTAL - CETESB. Relatório de estabelecimento de valores orientadores para solos e águas subterrâneas. São Paulo: CETESB, 2001. 73p.

\section{CONSELHO NACIONAL DE MEIO AMBIENTE}

- CONAMA. Resolução 375, de 29 de agosto de 2006. Acessado em 29 de novembro de 2011. Disponível em: < www.fundagres.org.br/ biossolido/images/.../res_conama37506.pdf>

CONCEIÇÃO, D.; RODRIGO, J.; BENTO, F.; SIMONETTI, A.; SELBACH, P.; CAMARGO, F. Redução de cromo hexavalente por bactérias isoladas de solos contaminados com cromo. Revista Ciência Rural, Santa Maria, RS, v.37, n.6, p.1661-1667, 2007.

EMPRESA BRASILEIRA DE PESQUISA AGROPECUÁRIA - EMBRAPA. Centro Nacional de Pesquisa de Solos. Manual de métodos de análises de solo. 2.ed. Rio de Janeiro, 1997. 212p.

EUCLYDES, R.F. Sistema de análises estatísticas e genéticas - SAEG. Central de Processamento de Dados. Viçosa, MG: UFV. 1983.

FACHIN, S.J.S.; HUBER, F.; SHIRAIWA, S.; BORGES, W.R.; MIGLIORINI, R.B. Aplicação de métodos geofísicos para identificar áreas contaminadas por resíduos de um curtume. Rev. Bras. Geof., São Paulo, SP, v.24, n.1, 2006.

FERREIRA,A.S.;CAMARGOF.A.O.;TEDESCO, M.J.; BISSANI, C.A. Alterações de atributos químicos e biológicos de solo e rendimento de milho e soja pela utilização de resíduos de curtume e carbonífero. Revista Brasileira de Ciência do Solo, Viçosa, MG, v.27, n.4, p.755-763, 2003.

FREITAS, T.C.M.; MELNIKOV, P. O uso e os impactos da reciclagem de cromo em indústrias de curtume em mato grosso do sul, Brasil. Engenharia Sanitária e Ambiental, Rio de Janeiro, v.11, n.4, p.305-310, 2006.

KONRAD, E.E.; CASTILHOS, D.D. Alterações químicas do solo e crescimento do milho decorrentes da adição de lodos de curtume. Revista Brasileira de Ciência do Solo, Viçosa, v.26, n.1, p.257-265, 2002.

LO MONACO, P.A.V.; MATOS, A.T.; MARTINEZ, H.E.P.; FERREIRA, P.A.; RAMOS, M.M. Características químicas do solo após a fertirrigação do cafeeiro com águas residuárias da lavagem e descascamento de seus frutos. Irriga. Botucatu, v.14, n.3, p.348-364, 2009.

MATOS, A.T. Práticas de qualidade do meio físico e ambiental. DEA: UFV, 2008. 67p. (Caderno didático, 34)

MATOS, A.T. Poluição ambiental: impactos no meio físico. Viçosa: Imprensa Universitária, 2010. 260p.

MATOS, A.T.; FONTES, M.P.F.; JORDÃO, C.P.; COSTA, L.M. Mobilidade e formas de retenção de metais pesados em latossolo Vermelho-Amarelo. Revista Brasileira de Ciência do Solo, Viçosa, MG, v.20, n.3, p.379-386, 1996.

NOVAIS, R.F.; SMYTH, T.J.; NUNES, F.N. Fósforo. In: NOVAIS, R.F.; ALVAREZ V., V.H.; BARROS, N.F.; FONTES, R.L.F.; CANTARUTTI, R.B.; NEVES, J.C.L. (Eds.) Fertilidade do Solo. Viçosa: Sociedade Brasileira de Ciência do Solo, 2007. 1017p.

OLIVEIRA, P.R., MATOS, A.T., LO MONACO, P.A.V. Desempenho agronômico e estado nutricional do capim mombaça fertirrigado com águas residuárias de curtume, Engenharia na Agricultura, Viçosa, MG, v.21 n.2, p.173-186, 2013.

PARFIT, R.L.; ATKINSON, R.J. \& SMART R.S.C. The mechanisms of phosphate fixation by 
iron oxides. Soil Sci. Soc. Am. J., v.39, p.837-841, 1975.

RAY, D.; EARY, L.; ZACHARA, E. Environmental chemistry of chromium. Science of Total Environmental, v.86, p.15-23, 1989.

RICHARDSON, A.E. Prospects for using soil microrganism to improve the acquisition of phosphorus by plants. Australian Journal of Plant Physiology, v.28, n.9, p.897-906, 2001.

RUTLAND, F.H. Environmental compatibility of chromium containing tannery and other leather product wastes at land disposal sites. Journal of American Leather Chemistry Association, v.86, p.364-373, 1991.

SANCHEZ, P.A. Properties and management of soils in the tropics. New York: John Wiley and Sons. 1976, 618p.

TREBIEN, D.O.P. Influência dos teores de matéria orgânica, óxidos de manganês facilmente redutíveis e umidade na oxidação do crômio no solo. 1994. 81f. Tese (Doutorado em Agronomia) - Curso de Pós-graduação em Solos, Universidade Federal do Rio Grande do Sul,, Porto Alegre, 1994. 